\title{
Mental Health Care Delivery for Older Adults in Rural Greece: Unmet Needs
}

\author{
Vaios Peritogiannis ${ }^{1} \quad$ Charalampos Lixouriotis $^{2}$ \\ ${ }^{1}$ Mobile Mental Health Unit of the Prefectures of Ioannina and \\ Thesprotia, Society for the Promotion of Mental Health in Epirus, \\ Ioannina, Greece \\ ${ }^{2}$ Health Center of Distomo, General Hospital of Livadia, Distomo, \\ Greece
}

\begin{abstract}
Address for correspondence Vaios Peritogiannis, MD, MSc, PhD, Mobile Mental Health Unit of the prefectures of Ioannina and Thesprotia, Society for the Promotion of Mental Health in Epirus, Moulaimidou Str 1, 45444 loannina, Greece (e-mail: vaios.peritogiannis@medai.gr).
\end{abstract}

\begin{abstract}
Keywords

- mental health care

- mobile mental health units

- older adults

- rural areas

Mental disorders may go unrecognized and undertreated in older adults. This is the rationale for the launch of specialized mental health services for the elderly in high resourced settings. Rural areas, however, do not receive adequate mental health care owing to socioeconomic and geographical reasons, and this is the case of rural Greece, where research on mental health of the elderly is scarce. This article discusses the challenges of providing mental health care for older adults in rural Greece and the available options. Care can be delivered through the existing rural mental health services that are the mobile mental health units and through the primary care physicians. Training in psychogeriatrics for the personnel of the former and in mental health for the latter is warranted.
\end{abstract}

\section{Introduction}

The population of older adults is steadily increasing, and this is a major challenge for the health systems globally. Old age is associated with certain age-related neuropsychiatric disorders, such as dementia, and older adults are susceptible to other mental disorders as well. Yet, even common mental disorders, such as depression may remain unrecognized in this population and once diagnosed, only a minority of patients receive adequate treatment. ${ }^{1}$ Moreover, the delivery of mental health care for older patients may be challenging. Old people may delay or even fail to contact mental health services for several reasons associated with age, such as cognitive decline and physical morbidity, ${ }^{2}$ and this may be even more relevant for those living in rural and remote areas, which mostly lack adequate mental health services.

\section{Mental Health Care Delivery for Older Adults by Specialized Services}

To address the mental health needs of the vulnerable population of older adults, several Western countries have launched specialized mental health services for those patients. A previous systematic review suggested that home-based mental health treatment for older adults is effective in improving psychopathology. ${ }^{3}$ In the state of Victoria, Australia, aged persons' mental health services have evolved over the past decades to well-structured and organized system of services across both metropolitan and rural regions. ${ }^{4}$ Recently, Reifler and Bruce ${ }^{5}$ presented 10 long-standing and successful programs that provided home-based services to mentally ill older adults in the United States. Moreover, in the United Kingdom, where the implementation of community mental health teams (CMHTs) has become the cornerstone of mental health services for older people, research has been undertaken to elucidate the factors that would improve feasibility and effectiveness. ${ }^{6}$ In addition, a framework for an evidence-based model of CMHTs for older people has been provided, which favored domiciliary assessment and team working involving health and social care staff. ${ }^{7}$

Several challenges in providing mental health care for older adults have been recorded. Futeran and Drapen ${ }^{8}$ studied 97 older adults who received treatment by specialized services and found that the majority of social needs of the patients were unmet. Cummings ${ }^{9}$ proposed that enhanced training of mental health professionals is essential so that adequate services may be provided to the vulnerable population of older adults. However, financial resources ${ }^{5}$ and 
staffing ${ }^{10}$ have been recognized as challenges affecting feasibility of specialized mental health care for older adults.

\section{Rural Areas' Perspective}

It is widely recognized that rural and remote areas do not receive adequate mental health care due to socioeconomic and geographical reasons, and distant facilities. ${ }^{11}$ Moreover, it has been suggested that even moderate distance may reduce the utilization of community-based mental health services. ${ }^{12}$ Other challenges in providing efficient mental health services in rural areas, such as difficulties in recruiting, retaining, and developing a trained workforce have been also recorded. ${ }^{13}$

It is also possible that the lack of specialized services in rural areas affects patients' outcomes, as supported by the literature on other medical conditions. For instance, a recent study in the United States reported that patients who sustain traumatic brain injury in rural, predominantly low-resource environments have a significantly higher risk of poor outcome (i.e., death) than those in urban, high-resource environments..$^{14}$ All these notions may be even more relevant in older rural residents.

\section{The Current State of Research on Mental Health Needs of Older Adults in Greece}

Research on mental health in older adults in Greece is scarce, with the exception of dementia. ${ }^{15-17}$ Some of the few epidemiologic studies have yielded worrying results. In a large international survey in 13,498 older people from nine European countries, it was found that residents in Italy, Greece, and Spain have the worst mental health, that is, high rates of depressive symptoms and low rates of well-being. ${ }^{18}$ This study presented data from 2004 that is before the emerge of the economic crisis which largely affected Greece and has been associated with increased prevalence of several common mental disorders. ${ }^{19,20}$ Other recent research on older adults in Greece revealed high rates of depressive symptoms ${ }^{21}$ and this is also the case of older rural residents. ${ }^{22}$ Importantly, research suggested that there is a remarkable underdetection of depressive symptoms in older adults in Greece. ${ }^{21}$ Most recently, a study in Crete, Southern Greece, found that there was an increase in suicide rates in middle-aged and elderly men between 1999 and 2013. Most importantly, suicide mortality rates have decreased in Western Crete and increased in Eastern Crete, an area where the network of community mental health services is markedly underdeveloped. ${ }^{23}$

Despite the reported needs, preventive interventions for mental health of the elderly have not been adequately developed in the context of psychiatric reform in Greece, ${ }^{24}$ and serious deficiencies in the provision of care for old people has been recorded. ${ }^{25}$ In fact, only a few efforts have been made to address those needs. Those initiations mostly involve the development of specialized outpatient services for patients with dementia ${ }^{26}$ and a few outpatient services for the elderly as part of the psychiatric departments in some general hospitals. All these services have been developed in urban settings. The problem is even more intense in rural and remote areas, the population of which do not receive adequate mental health care due to lack of services or distant facilities. ${ }^{27}$ Importantly, older adults comprise a large proportion of the population in those areas. ${ }^{28}$ Conceivably, mental health care delivery for older adults in rural areas of Greece is particularly challenging.

\section{The Case of Mental Health Services in Rural Areas in Greece}

Health care delivery in rural Greece is mostly based on primary health care, ${ }^{29}$ and older adults are frequently examined for medical problems and been prescribed medications by primary care physicians. However, there is ample evidence that primary care physicians have difficulties in diagnosing and treating mental disorders. Primary health care physicians may often not diagnose and address properly even common mental disorders such as depression, ${ }^{30,31}$ and this is probably the case of psychogeriatric syndromes as well.

To address the rural areas' mental health needs, the Greek state has launched several multidisciplinary teams, the so-called mobile mental health units (MMHUs) over the past decades. MMHUs are low-cost services because they deliver generic mental health services and they use the infrastructures and resources of the well-established primary health care system in those areas. ${ }^{32,33}$ Those MMHUs are mostly focus on patients with severe and chronic mental disorders, such as psychotic disorders, but in fact, they treat all referred patients, regardless of diagnosis, since they are the only mental health services in those areas.

\section{Implications for Mental Health Care}

It has been suggested that the psychiatric reform in Greece is still incomplete, and several specialized services, including geriatric mental health services are underdeveloped. The situation is further complicated by the impact of the financial crisis that has led to increased demand for services, funding difficulties, and staff shortages. ${ }^{34}$ Taking into account the economic restrictions and budget cuts for mental health, the development of specialized services for older adults in rural areas in Greece seems unlikely at present. Currently, the specialization in geriatric psychiatry is not developed in Greece, but even if there were adequate number of trained workforce, working in rural areas has several adversities for health professionals ${ }^{13}$ and may not be attractive, and this would raise obstacles in staffing of rural mental health services.

The delivery of mental health services for older adults living in those areas can be pursued through the existing services that are the MMHUs. Those MMHUs regularly examine and treat older rural residents, and there is some evidence that they may trace and treat homebound older adults through domiciliary visits, who would otherwise remain undiagnosed and untreated. ${ }^{35,36}$ For the delivery of effective services to older adults, MMHUs should incorporate principles and skills of psychogeriatric care in regular clinical practice. This could be achievable through further training of their personnel in psychogeriatrics and training in general 
medical conditions as those are commonly encountered in the elderly in routine clinical practice. ${ }^{37}$

The importance of the contribution of primary health care physicians in the detection and management of mental disorders in older adults should be also highlighted. Primary care physicians in rural areas regularly examine and treat elderly patients, but mental disorders are often undetected in primary care settings. ${ }^{30,31}$ The phenomenon is accounted for by several reasons, including reluctance of primary health care physicians to work with people with mental disorders, reduced time availability, and inadequate supervision of primary care staff by mental health professionals. ${ }^{38}$ Caring for all psychiatric syndromes in the elderly is particularly demanding for primary care physicians and is an unfeasible goal, but at least they could be aware of the nontypical clinical presentation of various psychiatric syndromes in the elderly and properly arrange referral to specialized mental health services that are the MMHUs. This could be attained through appropriate training and support. For instance, the Australian government has implemented the Rural Clinical School Program, for the support of the rural health workforce. ${ }^{39}$ In Greece, there have been several initiations for primary care physicians' training in mental health, and it has been suggested that after intensive education programs, they may become efficient in early diagnosis and effective management of mental disorders. ${ }^{40}$

It has been reported that primary care physicians' training in mental health per se may not be sufficient for the improvement of outcome in patients with common mental disorders. ${ }^{41}$ The need for access to psychotherapeutic and psychiatric expertise and collaboration with psychologists and psychiatrists has been recognized ${ }^{42}$ yet several difficulties in communication between primary care and mental health care services and in referrals have been described in the literature. ${ }^{43}$ However, in the case of MMHUs in rural Greece, these barriers are less relevant. MMHUs are locally based and have been integrated successfully within the primary care system, thus facilitating referrals and cooperation. ${ }^{44}$

\section{Conclusion}

Mental health care delivery for older adults in rural areas in Greece is still challenging, in an era of economic crisis and limited resources. Till the introduction of specialized teams, the best chance of providing quality mental health services for older adults in rural Greece is to invest on the preexisting services that are the MMHUs. The workforce of those multidisciplinary units should be additionally trained in psychogeriatric care. The enhancement of the co-operation among primary care and mental health professionals could provide a unique opportunity for on-site training of the former in psychiatric and psychogeriatric issues. This would facilitate appropriate treatment of mental disorders by primary care physicians and timely referral to the MMHUs when needed.

\section{Authors' Contributions}

All the authors have made equal contribution to the article.

\section{Funding}

None.

\section{Conflict of Interest}

None declared.

\section{References}

1 Licht-Strunk E, Beekman ATF, de Haan M, van Marwijk HW. The prognosis of undetected depression in older general practice patients. A one year follow-up study. J Affect Disord 2009;114(1-3):310-315

2 Wang PS, Berglund P, Olfson M, Pincus HA, Wells KB, Kessler RC. Failure and delay in initial treatment contact after first onset of mental disorders in the National Comorbidity Survey Replication. Arch Gen Psychiatry 2005;62(6):603-613

3 Van Citters AD, Bartels SJ. A systematic review of the effectiveness of community-based mental health outreach services for older adults. Psychiatr Serv 2004;55(11):1237-1249

4 Loi S, Hassett A. Evolution of aged persons mental health services in Victoria: the history behind their development. Australas J Ageing 2011;30(4):226-230

5 Reifler BV, Bruce ML. Home-based mental health services for older adults: a review of ten model programs. Am J Geriatr Psychiatry 2014;22(3):241-247

6 Wilberforce M, Harrington V, Brand C, Tucker S, Abendstern M, Challis D. Towards integrated community mental health teams for older people in England: progress and new insights. Int J Geriatr Psychiatry 2011;26(3):221-228

7 Abendstern M, Harrington V, Brand C, Tucker S, Wilberforce $\mathrm{M}$, Challis D. Variations in structures, processes and outcomes of community mental health teams for older people: a systematic review of the literature. Aging Ment Health 2012;16(7):861-873

8 Futeran S, Draper BM. An examination of the needs of older patients with chronic mental illness in public mental health services. Aging Ment Health 2012;16(3):327-334

9 Cummings SM. Treating older persons with severe mental illness in the community: impact of an interdisciplinary geriatric mental health team. J Gerontol Soc Work 2009;52(1):17-31

10 McAlpine L, Bailey A, Milward K, Blewett C. Recruitment into old age psychiatry. BJPsych Bull 2019;43(3):131-135

11 Thornicroft G, Semrau M, Alen A, et al, eds. Community Mental Health: Putting Policy into Practice Globally. New York, NY: Willey-Blackwell; 2011

12 Zulian G, Donisi V, Secco G, Pertile R, Tansella M, Amaddeo F. How are caseload and service utilisation of psychiatric services influenced by distance? A geographical approach to the study of community-based mental health services. Soc Psychiatry Psychiatr Epidemiol 2011;46(9):881-891

13 Moore T, Sutton K, Maybery D. Rural mental health workforce difficulties: a management perspective. Rural Remote Health 2010;10(3):1519

14 Brown JB, Kheng M, Carney NA, Rubiano AM, Puyana JC. Geographical disparity and traumatic brain injury in America: rural areas suffer poorer outcomes. J Neurosci Rural Pract 2019;10(1):10-15

15 Mougias AA, Politis A, Lyketsos CG, Mavreas VG. Quality of life in dementia patients in Athens, Greece: predictive factors and the role of caregiver-related factors. Int Psychogeriatr 2011;23(3):395-403

16 Anastasiou CA, Yannakoulia M, Kosmidis MH, et al. Mediterranean diet and cognitive health: initial results from the Hellenic Longitudinal Investigation of Ageing and Diet. PLoS One 2017; 12(8): $\mathrm{e} 0182048$

17 Kosmidis MH, Vlachos GS, Anastasiou CA, et al. Dementia prevalence in Greece: the Hellenic Longitudinal Investigation 
of Aging and Diet (HELIAD). Alzheimer Dis Assoc Disord 2018;32(3):232-239

18 Ploubidis GB, Grundy E. Later-life mental health in Europe: a country-level comparison. J Gerontol B Psychol Sci Soc Sci 2009;64(5):666-676

19 Economou M, Madianos M, Peppou LE, Patelakis A, Stefanis CN. Major depression in the era of economic crisis: a replication of a cross-sectional study across Greece. J Affect Disord 2013;145(3):308-314

20 Simou E, Koutsogeorgou E. Effects of the economic crisis on health and healthcare in Greece in the literature from 2009 to 2013: a systematic review. Health Policy 2014;115(2-3):111-119

21 Argyropoulos K, Bartsokas C, Argyropoulou A, Gourzis P, Jelastopulu E. Depressive symptoms in late life in urban and semi-urban areas of South-West Greece: an undetected disorder? Indian J Psychiatry 2015;57(3):295-300

22 Andriopoulos P, Lotti-Lykousa M, Pappa E. Papadopoulos AA, Niakas D. Depression, quality of life and primary care: a cross-sectional study. J Epidemiol Glob Health 2013;3(4):245-252

23 Basta M, Vgontzas A, Kastanaki A, et al. 'Suicide rates in Crete, Greece during the economic crisis: the effect of age, gender, unemployment and mental health service provision' BMC Psychiatry 2018;18(1):356

24 Christodoulou G. Psychiatric reform revisited. World Psychiatry 2009;8(2):121-122

25 Christodoulou GN, Ploumpidis DN, Christodoulou NG, Anagnostopoulos DC. The state of psychiatry in Greece. Int Rev Psychiatry 2012;24(4):301-306

26 Papasozomenou C, Poptsi E, Tabaki EM, Tsolaki M. The operation of the Day Care Centre of Alzheimer Hellas "Saint Helen" and of the Memory Clinic of Papanikolaou General Hospital from 2007 to 2017. Hell J Nucl Med 2017;20(Suppl):136-145

27 Madianos MG, Zacharakis C, Tsitsa C, Stefanis C. The mental health care delivery system in Greece: regional variation and socioeconomic correlates. J Ment Health Policy Econ 1999;2(4):169-176

28 Hellenic Statistical Authority. Available at: www.statistics.gr. Assessed April 10, 2019

29 Economou C. Greece: health system review. Health Syst Transit 2010;12(7):1-177

30 Tylee A, Walters P. Underrecognition of anxiety and mood disorders in primary care: why does the problem exist and what can be done? J Clin Psychiatry 2007;68(Suppl 2):27-30
31 Mitchell AJ, Vaze A, Rao S. Clinical diagnosis of depression in primary care: a meta-analysis. Lancet 2009;374(9690):609-619

32 Peritogiannis V, Mavreas V. Community mental health teams in Greece: The paradigm of mobile mental health units. Archives of Hellenic Medicine 2014;31:71-76

33 Stylianidis S, Pantelidou S, Poulios A, Lavdas M, Lamnidis N, Mobile mental health units on the islands: the experience of Cyclades. In: Stylianidis S, ed. Social and Community Psychiatry. Basel, Switzerland: Springer; 2016 167-191

34 Giannakopoulos G, Anagnostopoulos DC. Psychiatric reform in Greece: an overview. BJPsych Bull 2016;40(6):326-328

35 Peritogiannis V, Lekka M, Grammeniati A, et al. Home-based mental health care for the elderly in a rural area in Greece. Psychiatry Clin Neurosci 2013;67(6):458-459

36 Peritogiannis V, Tatsioni A, Manthopoulou T, Mavreas V. Mental healthcare for older adults in rural Greece. Int Psychogeriatr 2016;28(4):698-700

37 Peritogiannis V, Manthopoulou T, Gogou A, Mavreas V. Mental healthcare delivery in rural Greece: a 10-year account of a mobile mental health unit. J Neurosci Rural Pract 2017;8(4):556-561

38 Anonymous. What is primary care mental health?: WHO and Wonca Working Party on Mental Health. Ment Health Fam Med 2008;5(1):9-13

39 McGirr J, Seal A, Barnard A, et al. The Australian Rural Clinical School (RCS) program supports rural medical workforce: evidence from a cross-sectional study of 12 RCSs. Rural Remote Health 2019;19(1):4971

40 Argyriadou S, Lionis C. Research in primary care mental health in Greece. Ment Health Fam Med 2009;6(4):229-231

41 Sikorski C, Luppa M, König HH, van den Bussche H, Riedel-Heller SG. Does GP training in depression care affect patient outcome? - A systematic review and meta-analysis. BMC Health Serv Res 2012;12:10

42 Fleury MJ, Imboua A, Aubé D, Farand L, Lambert Y. General practitioners' management of mental disorders: a rewarding practice with considerable obstacles. BMC Fam Pract 2012;13:19

43 Durbin J, Barnsley J, Finlayson B, et al. Quality of communication between primary health care and mental health care: an examination of referral and discharge letters. J Behav Health Serv Res 2012;39(4):445-461

44 Peritogiannis V, Lixouriotis C, Mavreas V. The integration of mental health services into primary health care in Greece. Archives of Hellenic Medicine 2014;31:669-677 